\title{
Unbalanced Transportation Problems in Fuzzy Environment using Centroid Ranking Technique
}

\author{
R. K. Saini \\ Department of Mathematical \\ Sciences and Computer \\ Applications, Bundelkhand \\ University, Jhansi, India
}

\author{
Atul Sangal \\ Research Scholar \\ Banasthali University, \\ Banasthali, Rajasthan, India
}

\author{
Om Prakash \\ Department of Mathematics, \\ IIT Patna, Bihar, India
}

\begin{abstract}
In the present paper a new method proposed for the solution of unbalanced transportation problems with Trapezoidal Shaped Generalized Fuzzy Numbers ( $T_{\mathrm{P}} \mathrm{SGFN}$ ) using centroid ranking technique via zero suffix method. Numerical examples show that this technique offers effective way for handing the unbalanced fuzzy transportation problem with imprecise render and requirement condition. The advantage of the proposed method over the existing methods is to find fuzzy optimal solution does not involve only the dummy destination. The method has simple algorithms for computed and the study is checked with numerical examples.
\end{abstract}

\section{Keywords}

Unbalanced Transportation Problems, Trapezoidal Shaped Generalized Fuzzy Number, Centroid Ranking Technique, Zero Suffix Method.

\section{AMS Subject Classification:} 90B06, 90C90, 90C70.

\section{INTRODUCTION}

Transportation problems are solved with the assumptions that the parameters of the transportation problem are specified in crisp environment. The parameters of the transportation problem are not always exactly known and stable. This imprecision may follow from the lack of exact information, uncertainty in judgment etc.

Zadeh [25] introduced the notion of fuzziness, that was reinforced by Bellman and Zadeh [5]. Hitchcock [13] originally developed the basic transportation problem. Appa [2] discussed several variations of the transportation problem. Zimmermann [27] fuzzy linear programming has developed into seven fuzzy optimization methods for solving transportation problems. In [20] O'heigeartaigh proposed a new algorithm for the solution of transportation problems where the capacities and requirements are fuzzy numbers with linear triangular membership functions. The concept of optimal solution for the transportation problem with fuzzy coefficients expressed as fuzzy numbers are proposed by Chanas and Kuchta [6], for obtaining the optimal solution by developing an algorithm. Saad \& Abbas [24] discussed an algorithm for solving the transportation problems in fuzzy environment. By using all triangular fuzzy numbers as parameters, Das \& Baruah [7] proposed Vogel's approximation method to find the fuzzy initial basic feasible solution of fuzzy transportation problems. By transforming the fuzzy parameters into crisp parameters, Basirzadeh [4] used the classical algorithms to find the fuzzy optimal solution of fully fuzzy transportation problems. To find the fuzzy optimal solution of fuzzy transportation problems, where trapezoidal fuzzy numbers represent all the parameters, Pandian \& Natrajan [21, 22] proposed a new algorithm, namely fuzzy zero point method. Gani et al [12] obtained the fuzzy optimal solution of fuzzy transportation problems having parameters as trapezoidal fuzzy numbers. For more details see $[1,8,9,10,16,17,19,23,27]$.

For solving unbalanced fuzzy transportation problems, two cases may arise as either the total demand is more than the total supply or vice-versa. In case of excess supply, it may happen sometimes that there is no enough storage place for the excess commodity, we wish to transport it to the destinations for the further demand. or in case of excess demand, wish to transport it for future supply. Here we add a dummy destination, where the excess availability is transported. Because the dummy destination does not have any existence in reality, so it is not possible to find that the excess available product should be transported to which the destination at a minimum cost.

\section{PRELIMINARIES}

In this section, some basic definitions, arithmetic operations and comparison of generalized trapezoidal fuzzy numbers are presented.

\subsection{Definition}

Let $\mathrm{R}$ is a universal set of real numbers. A fuzzy set $\$$ defined is said to be a fuzzy number if its membership function has the following characteristics:

(i) $\mu_{\AA_{0}}: \mathrm{R} \rightarrow[0,1]$ is continuous

(ii) $\mu_{\AA_{0}}(\mathrm{x})=0$ for all $\mathrm{x} \in(-\infty, \mathrm{a}] \cup[\mathrm{d}, \infty)$

(iii) $\mu_{\&_{0}}(\mathrm{x})$ is strictly increasing on [a,b] and strictly decreasing on $[\mathrm{c}, \mathrm{d}]$

(iv) $\mu_{\alpha_{0}}(\mathrm{x})=1$ for all $\mathrm{x} \in[\mathrm{b}, \mathrm{c}]$, where $\mathrm{a} \leq \mathrm{b} \leq \mathrm{c} \leq \mathrm{d}$

\subsection{Definition}

Let $\mathrm{R}$ is a universal set of real numbers. A fuzzy set $\mathbb{R}^{\circ}$ is said to be generalized fuzzy number if its membership function has the following characteristics:

(i) $\mu_{\AA_{0}}: \mathrm{R} \rightarrow[0,1]$ is continuous

(ii) $\mu_{\&_{0}}(\mathrm{x})=0$ for all $\mathrm{x} \in(-\infty, \mathrm{a}] \cup[\mathrm{d}, \infty)$

(iii) $\mu_{k_{0}}(\mathrm{x})$ is strictly increasing on $[\mathrm{a}, \mathrm{b}]$ and strictly decreasing on $[\mathrm{c}, \mathrm{d}]$

(iv) $\mu_{8_{0}}(\mathrm{x})=\mathrm{w}$ for all $\mathrm{x} \in[\mathrm{b}, \mathrm{c}]$, where $0<\mathrm{w} \leq 1$ 


\subsection{Definition}

A fuzzy set $\AA^{\circ}$ of the universe of discourse $\mathrm{X}$ is called a normal fuzzy set if there exist at least one $\mathrm{x} \in \mathrm{X}$ such that $\mu_{\AA_{0}}(\mathrm{x})=\mathrm{w}=1$.

\subsection{Definition}

The fuzzy set $\&$ is convex if and only if, for any $\mathrm{x}_{1}, \mathrm{x}_{2} \in \mathrm{X}$, the membership function of $\AA^{\circ}$ satisfies the inequality

$\mu_{\mathrm{A}}\left\{\lambda \mathrm{x}_{1}+(1-\lambda) \mathrm{x}_{2}\right\} \geq \min \left\{\mu_{\mathrm{A}}\left(\mathrm{x}_{1}\right), \mu_{\mathrm{A}}\left(\mathrm{x}_{2}\right)\right\}, 0 \leq \lambda \leq 1$.

\subsection{Definition (Trapezoidal Fuzzy \\ Number)[15]:}

A trapezoidal fuzzy number $\AA^{(}(\mathrm{x})$, it can be represented by $\AA(\mathrm{a}, \mathrm{b}, \mathrm{c}, \mathrm{d} ; 1)$ as given by

$$
\AA^{\prime}(a, b, c, d ; 1)= \begin{cases}\frac{(x-a)}{(b-a)}, & a \leq x \leq b \\ 1, & b \leq x \leq c \\ \frac{(d-x)}{(d-c)}, & c \leq x \leq d \\ 0, & \text { otherwise }\end{cases}
$$

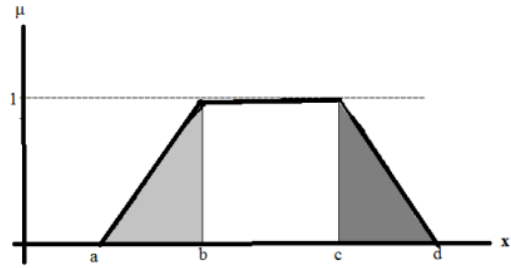

Fig. 1:Trapezoidal Fuzzy Number $\AA($ a, b, c, d;1)

The $\alpha$-cut of a fuzzy number $\AA^{(}(\mathrm{x})$ is defined as

$$
\mathbb{R}^{\alpha \alpha}(\mathrm{x})=\{\mathrm{x}: \mu(\mathrm{x}) \geq \alpha, \alpha \in[0,1]\}
$$

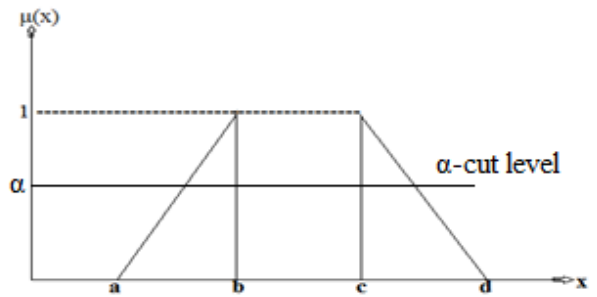

Fig. $2: \alpha-$ cut of $\AA(a, b, c, d ; 1)$

\subsection{Definition}

A generalized fuzzy number $\AA^{\circ}=(\mathrm{a}, \mathrm{b}, \mathrm{c}, \mathrm{d} ; \mathrm{w})$ is said to be a generalized trapezoidal fuzzy number if its membership function is given by

$$
\AA^{\prime}(\mathrm{a}, \mathrm{b}, \mathrm{c}, \mathrm{d} ; \mathrm{w})= \begin{cases}\frac{\mathrm{w}(\mathrm{x}-\mathrm{a})}{(\mathrm{b}-\mathrm{a})}, & \mathrm{a} \leq \mathrm{x} \leq \mathrm{b} \\ \mathrm{w}, & \mathrm{b} \leq \mathrm{x} \leq \mathrm{c} \\ \frac{\mathrm{w}(\mathrm{d}-\mathrm{x})}{(\mathrm{d}-\mathrm{c})}, & \mathrm{c} \leq \mathrm{x} \leq \mathrm{d} \\ 0, & \text { otherwise }\end{cases}
$$

\subsection{Remark}

A generalized trapezoidal fuzzy number $\AA^{\circ}=(\mathrm{a}, \mathrm{b}, \mathrm{c}, \mathrm{d}$; w $)$ can be explained as follows:

(i) According to decision maker the cost (or demand or supply or profit etc.) of the product will be greater than $\mathbf{m}$ units and less than $\mathbf{n}$ units.

(ii) In favor of the cost (or demand or supply or profit etc.), the decision maker is $\mathrm{w} \times 100 \%$ which will be greater than or equal to $\mathbf{n}$ units and less than or equal to $\mathbf{p}$ units.

(iii) For the remaining values of cost (or demand or supply or profit etc.), the percentage of the favourness can be obtained as $\mathrm{x}=\AA(\mathrm{a}, \mathrm{b}, \mathrm{c}, \mathrm{d} ; \mathrm{w}) \times 100$, where $\mathrm{x}$ represents the cost (or demand or supply or profit etc.).

\section{ARITHMETIC OPERATIONS}

The arithmetic operations between two generalized trapezoidal fuzzy numbers, defined on universal set of real numbers $\mathrm{R}$ is computed as follows:

Let $\AA^{\circ}=\left(\mathrm{a}_{1}, \mathrm{~b}_{1}, \mathrm{c}_{1}, \mathrm{~d}_{1} ; \mathrm{w}_{1}\right)$ and $\mathrm{B}^{\circ}=\left(\mathrm{a}_{2}, \mathrm{~b}_{2}, \mathrm{c}_{2}, \mathrm{~d}_{2} ; \mathrm{w}_{2}\right)$ be two generalized trapezoidal fuzzy numbers then

$\mathrm{A}^{\circ} \oplus \mathrm{B}^{\circ}=\left(\mathrm{a}_{1}+\mathrm{a}_{2}, \mathrm{~b}_{1}+\mathrm{b}_{2}, \mathrm{c}_{1}+\mathrm{c}_{2}, \mathrm{~d}_{1}+\mathrm{d}_{2} ; \operatorname{minimum}\left(\mathrm{w}_{1}, \mathrm{w}_{2}\right)\right)$

$A$ ! $B^{\circ}=\left(a_{1}-a_{2}, b_{1}-b_{2}, c_{1}-c_{2}, d_{1}-d_{2} ; \operatorname{minimum}\left(w_{1}, w_{2}\right)\right)$

$A^{0} \otimes B^{\circ}=\left(a^{a}, b^{a}, c^{\mathfrak{a}}, d^{\mathfrak{a}} ; \operatorname{minimum}\left(\mathrm{w}_{1}, \mathrm{w}_{2}\right)\right)$,

where

$\mathrm{a}^{\mathrm{a}}=\operatorname{minimum}\left(\mathrm{a}_{1} \mathrm{a}_{2}, \mathrm{a}_{1} \mathrm{~d}_{2}, \mathrm{~d}_{1} \mathrm{a}_{2}, \mathrm{~d}_{1} \mathrm{~d}_{2}\right)$,

$b^{\mathfrak{a}}=\operatorname{minimum}\left(b_{1} b_{2}, b_{1} c_{2}, c_{1} b_{2}, c_{1} c_{2}\right)$,

$c^{a}=\operatorname{maximum}\left(b_{1} b_{2}, b_{1} c_{2}, c_{1} b_{2}, c_{1} c_{2}\right)$,

$\mathrm{d}^{\mathrm{a}}=\operatorname{maximum}\left(\mathrm{a}_{1} \mathrm{a}_{2}, \mathrm{a}_{1} \mathrm{~d}_{2}, \mathrm{~d}_{1} \mathrm{a}_{2}, \mathrm{~d}_{1} \mathrm{~d}_{2}\right)$

$$
\lambda \AA^{\circ}=\left\{\begin{array}{l}
\left(\lambda \mathrm{a}_{1}, \lambda \mathrm{b}_{1}, \lambda \mathrm{c}_{1}, \lambda \mathrm{d}_{1} ; \mathrm{w}_{1}\right), \lambda>0 \\
\left(\lambda \mathrm{d}_{1}, \lambda \mathrm{c}_{1}, \lambda \mathrm{b}_{1}, \lambda \mathrm{a}_{1} ; \mathrm{w}_{1}\right), \lambda<0
\end{array}\right.
$$

\section{USED SYMBOLS}

$\mathrm{m}$ : number of sources

$\mathrm{n}$ : number of destinations

$d_{l}$ : the fuzzy availability of the product at source $\mathrm{S}_{\mathrm{i}}$

$b_{j}^{o}$ : the fuzzy demand of the product at destination $\mathrm{D}_{\mathrm{j}}$

$\mathcal{E}_{i j}$ : the fuzzy cost for transporting one unit of the product from $S_{i}$ to $D_{j}$

$f_{i l}$ : the fuzzy quantity of the product to be transported from $\mathrm{S}_{\mathrm{i}}$ to $D_{j}$

$\mathscr{W}$ : dual variable corresponding to $\mathrm{i}^{\text {th }}$ source at (TP1)

$1 \%$ : dual variable corresponding to $\mathrm{j}^{\text {th }}$ destination at (TP1)

$\mathscr{W}_{i}$ : dual variable corresponding to $\mathrm{i}^{\text {th }}$ source at (TP2)

$1 \%$ : dual variable corresponding to $\mathrm{j}^{\text {th }}$ destination at (TP2) 


\section{NEW RANKING TECHNIQUE}

Here we are taking a new ranking method called centoid ranking method for the generalized fuzzy number for solving the transportation problems. This approach involves simple computational and is easily understandable. The centroid ranking method can explained easily in geometrical from. For understanding this method we make a figure:

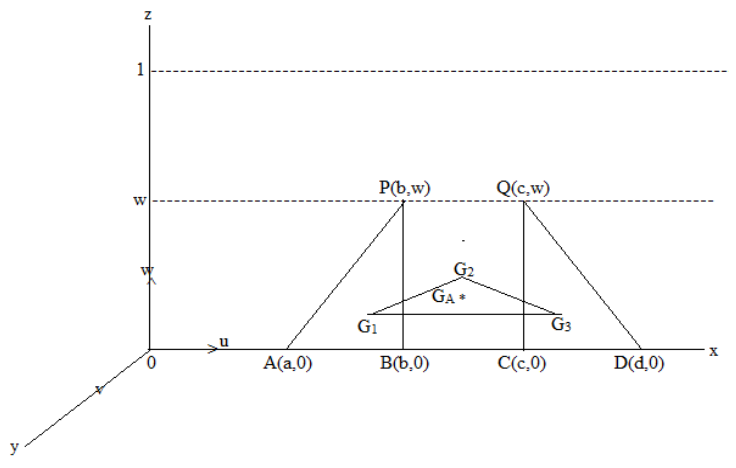

Fig. 3: Centoid Ranking Method

From the figure, it is simple that centoid method depends on trapezoidal + triangular fuzzy numbers. We can clearly see that in the above figure, triangular shaped figure APB, CQD and rectangular shaped figure BPQC merged in trapezoidal shaped figure APQDA. Let the centroid of $\triangle \mathrm{APB}$, rectangle BPQC, and $\triangle \mathrm{CQD}$ are $\mathrm{G}_{1}, \mathrm{G}_{2}$ and $\mathrm{G}_{3}$ respectively. The centroid $\mathrm{G}_{\AA^{\circ}}$ (suppose) of these centroids $\mathrm{G}_{1}, \mathrm{G}_{2}$ and $\mathrm{G}_{3}$ is taken as the point of reference, to define the ranking of generalized trapezoidal fuzzy number. The reason for selecting this point of reference is that each centroid point $G_{1}$, of triangle $\mathrm{APB}, \mathrm{G}_{2}$ of rectangle $\mathrm{BPQC}$ and $\mathrm{G}_{\mathrm{A}}$ of $\triangle \mathrm{AQBD}$ are balancing points of each individual plane figure and the centroid of these centroid points is a much more balancing point for a general trapezoidal fuzzy number. After calculating the ranking indices for the use of new ranking method, we apply the following formula for generalized trapezoidal fuzzy number, is

$$
\mathrm{R}(\AA)=\left(\frac{2 \mathrm{a}+7 \mathrm{~b}+7 \mathrm{c}+2 \mathrm{~d}}{18}\right)\left(\frac{7 \mathrm{w}}{18}\right) .
$$

\subsection{Remark [18]:}

Let $A^{o}=\left(a_{1}, b_{1}, c_{1}, d_{1} ; w_{1}\right)$ and $B^{\circ}=\left(a_{2}, b_{2}, c_{2}, d_{2} ; w_{2}\right)$ be two trapezoidal fuzzy numbers. Then

(i) $\AA_{1}^{\circ}$ f $\AA_{2}^{o}$, if $\mathrm{R}\left(\AA_{1}^{\circ}\right)$ f $\mathrm{R}\left(\AA_{2}^{o}\right)$,

(ii) $\AA_{1}^{o} \mathrm{p} \AA_{2}^{o}$, if $\mathrm{R}\left(\AA_{1}^{o}\right) \mathrm{p} \mathrm{R}\left(\AA_{2}^{o}\right)$

(iii) $\AA_{1}^{o} \approx \AA_{2}^{o}$, if $\mathrm{R}\left(\AA_{1}^{o}\right)=\mathrm{R}\left(\AA_{2}^{o}\right)$.

\subsection{Remark}

A generalized trapezoidal fuzzy number $\AA^{\circ}=(\mathrm{a}, \mathrm{b}, \mathrm{c}, \mathrm{d}$; w $)$ is said to be zero fuzzy number if and only if $\mathrm{R}(\AA)=0$ and is denoted by $Q$ C

\subsection{Remark}

A generalized trapezoidal fuzzy number $\AA^{\circ}=(\mathrm{a}, \mathrm{b}, \mathrm{c}, \mathrm{d} ; \mathrm{w})$ is said to be non-negative number if and only if $\mathrm{R}(\AA 9) \geq 0$ and is denoted by $\AA^{\circ} 0^{\circ}$ ?

\section{IMPROVED METHOD}

ZERO

SUFFIX

Here we introduce an improved zero suffix method for finding on optimal solution to the transportation problem as:

Step1 Construct the transportation table.

Step2 Subtract row minimum value from each row entries of the corresponding row in transportation table. The same process must be done for columns of the transportation table.

Step3 In the reduced cost matrix, there will be at least one zero in each row and each column. Find the suffix value of all the zero's in the cost matrix as follows:

$\mathrm{S}=\underline{\text { sum of the values }\left(\mathrm{c}_{\mathrm{ij}}\right) \text { of zero's in corresponding rowand column except itself }}$ No. of zeros

Step4 Choose the maximum of $\mathrm{S}$, if it has one maximum value then first supply to that demand corresponding to the cell. If it has more equal values then select $\left\{a_{i}, b_{j}\right\}$ and supply to that demand maximum possible.

Step5 After the above steps, the exhausted demands or supplies to be trimmed. The resultant matrix must possess at least one zero is each row and column, else repeat step 2.

Step6 Repeat steps 3 to 5 until the optimal solution is obtained.

\section{PROBLEM FORMULATION}

Consider an unbalanced trapezoidal shaped generalized fuzzy transportation problem $\left(\mathrm{T}_{\mathrm{P}} \mathrm{SGFTP}\right)$ having $\mathrm{m}$ sources $\mathrm{S}_{\mathrm{i}}$ with fuzzy availability $\mathscr{O}(1 \leq \mathrm{i} \leq \mathrm{m})$ and $\mathrm{n}$ destinations $\mathrm{D}_{\mathrm{j}}$ with fuzzy demand $b_{j}^{\circ}(1 \leq j \leq n)$. Each of the $m$ sources $S_{i}$ can transport to any of the $\mathrm{n}$ destinations $\mathrm{D}_{\mathrm{j}}$ at a transportation cost of $\varepsilon_{11}$ per unit. Let $\&_{\text {i1 }}$ be the fuzzy quantity of the product that should be transported from source $S_{i}$ to destination $\mathrm{D}_{\mathrm{j}}$. The transportation problem $\left(\mathrm{TP}_{1}\right)$ can be represented as follows:

$$
\begin{aligned}
& \text { Minimize } \sum_{\mathrm{i}=1}^{m} \sum_{\mathrm{j}=1}^{\mathrm{n}} \varepsilon_{\mathrm{i}} \otimes \mathbb{f}_{\mathrm{i}} \\
& \text { subject to } \sum_{\mathrm{j}=1}^{\mathrm{n}} \mathscr{\ell}_{\mathrm{ij}} \pm \mathscr{K}_{\mathrm{i}},(1 \leq \mathrm{i} \leq \mathrm{m}) \\
& \sum_{i=1}^{m} \mathrm{X}_{\mathrm{i}} \pm b_{j}^{o}, \quad(1 \leq \mathrm{i} \leq \mathrm{m})
\end{aligned}
$$

\subsection{Example}

Consider a transportation problem with 4 sources say $\mathrm{S}_{1}, \mathrm{~S}_{2}$, $\mathrm{S}_{3}, \mathrm{~S}_{4}$ and 4 destinations $\mathrm{D}_{1}, \mathrm{D}_{2}, \mathrm{D}_{3}, \mathrm{D}_{4}$ with unit costs of transporting the product from source $\mathrm{S}_{\mathrm{i}}(1 \leq \mathrm{i} \leq 4)$ to destination $D_{j}(1 \leq j \leq 4)$ The generalized fuzzy transportation cost matrix for unit quantity of product from $\mathrm{i}^{\text {th }}$ sources to $\mathrm{j}^{\text {th }}$ destinations is as given below: 
$\left(c_{\mathrm{ij}}\right)_{4 \times 4}=\left(\begin{array}{cccc}(5,7,3,4) & (3,2,4,7) & (2,1,4,9) & (9,8,14,13) \\ (12,11,6,2) & (15,9,6,4) & (10,9,8,7) & (14,10,11,8) \\ (4,9,6,7) & (1,8,9,15) & (13,12,3,11) & (8,7,4,1) \\ (6,3,9,4) & (7,11,13,9) & (8,10,12,15) & (11,1,2,3)\end{array}\right)$

Fuzzy availability (supply) of the product at sources are $(10,9,15,14),(16,10,7,5),(14,13,4,12)$ and $(12,2,3,4)$ and the fuzzy demand of the product to the destinations are $(14,13,8,3),(17,11,8,6),(15,14,5,13)$ and $(16,12,13,10)$. The product can be shipped from any source to any destination. Here we try to find the generalized fuzzy quantity of the product that should be transported from each source to each destination so that the total generalized fuzzy cost of transportation is minimum.

For the above transportation problem, the total generalized fuzzy demand is more than the total generalized fuzzy supply. So we first convert it to a balanced problem by adding a dummy source $\left(\mathrm{S}_{5}\right)$ with the corresponding unit transportation costs to be zero trapezoidal generalized fuzzy numbers and convert the constraint inequalities to equations. The balanced generalized fuzzy transportation problem in tabular form as follows:

Solution The fuzzy Transportation problems are given in Table-1

\begin{tabular}{|c|c|c|c|c|c|}
\hline Sources & $\mathbf{D}_{\mathbf{1}}$ & $\mathbf{D}_{\mathbf{2}}$ & $\mathbf{D}_{\mathbf{3}}$ & $\mathbf{D}_{\mathbf{4}}$ & Supply \\
$\mathbf{S}_{\mathbf{1}}$ & $(5,7,3,4)$ & $(3,2,4,7)$ & $(2,1,4,9)$ & $(9,8,14,1)$ & $(\mathbf{1 0 , 9 , 1 5 , 1 4})$ \\
$\mathbf{S}_{\mathbf{2}}$ & $(12,11,6,2)$ & $(15,9,6,4)$ & $(10,9,8,7)$ & $(14,10,11,8)$ & $(\mathbf{1 6}, \mathbf{1 0 , 7 , 5})$ \\
$\mathbf{S}_{\mathbf{3}}$ & $(4,9,6,7)$ & $(1,8,9,15)$ & $(13,12,3,11)$ & $(8,7,4,1)$ & $(\mathbf{1 4 , 1 3 , 4 , 1 2})$ \\
$\mathbf{S}_{\mathbf{4}}$ & $(6,3,9,4)$ & $(7,11,13,9)$ & $(8,10,12,15)$ & $(11,1,2,3)$ & $(\mathbf{1 2 , 2 , 3 , 4})$ \\
Demand & $(\mathbf{1 4 , 1 3 , 8 , 3})$ & $(\mathbf{1 7 , 1 1 , 8 , 6})$ & $(\mathbf{1 5 , 1 4 , 5 , 1 3})$ & $(\mathbf{1 6 , 1 2 , 1 3 , 1 0})$ & \\
\hline
\end{tabular}

Table-1: Unbalanced generalized fuzzy transportation problem

In conformation to model the fuzzy transportation problem can be formulated in the following mathematical form

$$
\begin{aligned}
& \operatorname{MinZ}=\mathrm{R}(5,7,3,4) \mathrm{x}_{11}+\mathrm{R}(3,2,4,7) \mathrm{x}_{12}+\mathrm{R}(2,1,4,9) \mathrm{x}_{13}+\mathrm{R}(16,23,33,46) \mathrm{x}_{14}+\mathrm{R}(12,11,6,2) \mathrm{x}_{21}+\mathrm{R}(15,9,6,4) \mathrm{x}_{22} \\
& +\mathrm{R}(10,9,8,7) \mathrm{x}_{23}+\mathrm{R}(14,10,11,8) \mathrm{x}_{24}+\mathrm{R}(4,9,6,7) \mathrm{x}_{31}+\mathrm{R}(1,8,9,15) \mathrm{x}_{32}+\mathrm{R}(13,12,3,11) \mathrm{x}_{33}+\mathrm{R}(8,7,4,1) \mathrm{x}_{34} \\
& +\mathrm{R}(6,3,9,4) \mathrm{x}_{41}+\mathrm{R}(7,11,13,9) \mathrm{x}_{42}+\mathrm{R}(8,10,12,15) \mathrm{x}_{43}+\mathrm{R}(11,1,2,3) \mathrm{x}_{44}
\end{aligned}
$$

Now for ranking, we take

$$
\mathrm{R}\left(\AA 9=\left(\frac{2 a+7 b+7 c+2 d}{18}\right)\left(\frac{7 \mathrm{w}}{18}\right)\right.
$$

For ranking the fuzzy numbers, we use centroid ranking method for $\mathrm{w}=0.5$ and applying as follows:

$\mathrm{R}\left(\mathrm{c}_{11}\right)=\mathrm{R}(5,7,3,4)=\left(\frac{2(5+5)+7(7+3)}{18}\right) \times\left(\frac{7(.5)}{18}\right)=0.950$

Proceeding similarly, the ranking indices for the cost $\mathcal{E}_{\mathrm{ij}}$ are calculated as:

$$
\begin{aligned}
& \mathrm{R}\left(\varepsilon_{p_{2}}\right)=\mathrm{R}(3,2,4,7)=0.669, \quad \mathrm{R}\left(\varepsilon_{p_{3}}\right)=\mathrm{R}(2,1,4,9)=0.507, \\
& \mathrm{R}\left(\varepsilon_{4}\right)=\mathrm{R}(9,8,14,1)=1.879 \text {, } \\
& \mathrm{R}\left(\mathscr{Q}_{21}\right)=\mathrm{R}(12,11,6,2)=1.587 \\
& \mathrm{R}\left(\mathscr{Q}_{22}\right)=\mathrm{R}(15,9,6,4)=1.544 \text {, } \\
& \mathrm{R}\left(\mathscr{E}_{\mathscr{Q}_{3}}\right)=\mathrm{R}(10,9,8,7)=1.652 \text {, }
\end{aligned}
$$

$$
\begin{aligned}
& \mathrm{R}\left(\mathcal{E}_{q_{4}}\right)=\mathrm{R}(14,10,11,8)=1.847, \mathrm{R}\left(\mathcal{E}_{q_{1}}\right)=\mathrm{R}(4,9,6,7)=1.371 \text {, } \\
& \mathrm{R}\left(\mathscr{E}_{3_{2}}\right)=\mathrm{R}(1,8,9,15)=1.631, \quad \mathrm{R}\left(\varepsilon_{3_{3}}\right)=\mathrm{R}(13,12,3,11)=1.652 \text {, } \\
& \mathrm{R}\left(\mathscr{G}_{4}\right)=\mathrm{R}(8,7,4,1)=1.026, \quad \mathrm{R}\left(\&_{41}\right)=\mathrm{R}(6,3,9,4)=1.080 \text {, } \\
& \mathrm{R}\left(\mathcal{E}_{42}\right)=\mathrm{R}(7,11,13,9)=2.160 \text {, } \\
& \mathrm{R}\left(\&_{43}\right)=\mathrm{R}(8,10,12,15)=2.160 \text {, } \\
& \mathrm{R}\left(\&_{44}\right)=\mathrm{R}(11,1,2,3)=0.529 \text {. }
\end{aligned}
$$

\section{Rank of all Demand}

$$
\begin{array}{ll}
\mathrm{R}(14,13,8,3)=1.955, & \mathrm{R}(17,11,8,6)=1.933, \\
\mathrm{R}(15,14,5,13)=2.041, & \mathrm{R}(16,12,13,10)=2.452 .
\end{array}
$$

\section{Rank of all Supply}

$$
\begin{array}{ll}
\mathrm{R}(10,9,15,14)=2.333, & \mathrm{R}(16,10,7,5)=1.739, \\
\mathrm{R}(14,13,4,12)=1.847, & \mathrm{R}(12,2,3,4)=0.723 .
\end{array}
$$




\begin{tabular}{|c|c|c|c|c|c|}
\hline Sources & $\mathrm{D}_{1}$ & $\mathrm{D}_{2}$ & $\mathrm{D}_{3}$ & $\mathrm{D}_{4}$ & Supply \\
$\mathrm{S}_{1}$ & 0.950 & $0.667(\mathbf{0 . 2 9 2})$ & $0.507(\mathbf{2 . 0 4 1})$ & 1.879 & $\mathbf{2 . 3 3 3}$ \\
$\mathrm{S}_{2}$ & $1.587(\mathbf{0 . 0 9 7})$ & $1.544(\mathbf{1 . 6 4 2})$ & 1.652 & 1.847 & $\mathbf{1 . 7 3 9}$ \\
$\mathrm{S}_{3}$ & $1.371(\mathbf{0 . 1 1 8})$ & 1.631 & 1.652 & $1.026(\mathbf{1 . 7 2 9})$ & $\mathbf{1 . 8 4 7}$ \\
$\mathrm{S}_{4}$ & 1.080 & 2.160 & 2.160 & $0.529(\mathbf{0 . 7 2 3})$ & $\mathbf{0 . 7 2 3}$ \\
$\mathrm{S}_{5}$ & $0.000(\mathbf{1 . 7 4 0})$ & 0.000 & 0.000 & 0.000 & $\mathbf{1 . 7 4 0}$ \\
Demand & $\mathbf{1 . 9 5 5}$ & $\mathbf{1 . 9 3 4}$ & $\mathbf{2 . 0 4 1}$ & $\mathbf{2 . 4 5 2}$ & \\
\hline
\end{tabular}

Table-2: Solution of balance generalized fuzzy transportation problem after ranking

\begin{tabular}{|c|c|c|c|c|c|}
\hline Sources & $\begin{array}{c}\mathbf{D}_{1} \\
(5,7,3,4)\end{array}$ & $\begin{array}{c}\mathbf{D}_{\mathbf{2}} \\
(3,2,4,7)(\mathbf{- 3}, \mathbf{4}, \mathbf{1}, \mathbf{- 1})\end{array}$ & $\begin{array}{c}\mathbf{D}_{\mathbf{3}} \\
(2,1,4,9)(\mathbf{1 5}, \mathbf{1 4}, \mathbf{5}, \mathbf{1 3})\end{array}$ & $\begin{array}{c}\mathbf{D}_{4} \\
(9,8,14,1)\end{array}$ & $\begin{array}{c}\text { Supply } \\
(10,9,15,14)\end{array}$ \\
\hline $\mathrm{S}_{2}$ & $(12,11,6,2)(\mathbf{3 4}, \mathbf{1 8}, \mathbf{- 1 5},-\mathbf{4 0})$ & $(15,9,6,4)(\mathbf{1 8}, \mathbf{1 0}, \mathbf{4}, \mathbf{9}$ & $(10,9,8,7)$ & $(14,10,11,8)$ & $(16,10,7,5)$ \\
\hline $\mathbf{S}_{3}$ & $(4,9,6,7)(\mathbf{1 6}, \mathbf{2},-\mathbf{5}, \mathbf{0})$ & $(1,8,9,15)$ & $(13,12,3,11)$ & $(8,7,4,1)(\mathbf{1 2}, \mathbf{9}, \mathbf{1 1},-\mathbf{2})$ & $(14,13,4,12)$ \\
\hline $\mathrm{S}_{4}$ & $(6,3,9,4)$ & $(8,10,12,15)$ & $(8,10,12,15)$ & $(11,1,2,3)(\mathbf{1 2}, \mathbf{2}, \mathbf{3}, \mathbf{4})$ & $(12,2,3,4)$ \\
\hline $\mathbf{S}_{5}$ & $(0,0,0,0)(\mathbf{2 2}, \mathbf{2 1}, \mathbf{0},-\mathbf{2 0})$ & $(0,0,0,0)$ & $(0,0,0,0)$ & $(0,0,0,0)$ & $(22,21,0,-20)$ \\
\hline$\overline{\text { Demand }}$ & $\overline{(14,13,8,3)}$ & $\overline{(17,11,8,6)}$ & $\overline{(15,14,5,13)}$ & $\overline{(16,12,13,10)}$ & \\
\hline
\end{tabular}

Table-3: Solution of balance generalized fuzzy transportation problem by zero suffix method

The generalized fuzzy optimal solutions are

$$
\begin{array}{ll}
X_{11}=(7,6,-3,-13), & X_{12}=(12,4,-2,-10), \\
X_{13}=(15,14,5,13), & X_{22}=(16,10,7,5), \\
X_{31}=(16,2,-5,0), & X_{34}=(12,9,11,-2), \\
X_{44}=(12,2,3,4), & X_{51}=(27,21,0,-20) .
\end{array}
$$

The total generalized fuzzy optimal cost is

$141,461,1132)$.

$$
\mathrm{z} \quad=\quad(-443,-
$$

\section{8. PROPOSED METHOD}

In this section, we proposed a method to solve the unbalanced $\left(\mathrm{T}_{\mathrm{P}} \mathrm{SGFTP}\right)$ in which total generalized fuzzy demand is more than the total generalized fuzzy supply. We first prove the following theorem.

\subsection{Theorem}

Let $\left(\mathrm{TP}_{2}\right)$ be the fuzzy linear formulation of balanced ( $\mathrm{T}_{\mathrm{P}} \mathrm{SGFTP}$ ) obtained by adding a dummy source $\mathrm{S}_{\mathrm{m}+1}$ with unit fuzzy transportation costs $\mathrm{c}_{(\mathrm{m}+1) \mathrm{j}}=\min _{1 \leq \mathrm{i} \leq \mathrm{m}}\left(\mathcal{E}_{\mathrm{j} j}\right), 1 \leq \mathrm{j} \leq \mathrm{n}, \mathrm{a}$ dummy destination $\mathrm{D}_{\mathrm{n}+1}$ with $\mathrm{c}_{\mathrm{i}(\mathrm{n}+1)}=\min _{1 \leq \mathrm{i} \leq \mathrm{n}}\left(\mathcal{E}_{\mathrm{i})}\right), 1 \leq \mathrm{i} \leq \mathrm{m}$, to $\left(\mathrm{TP}_{1}\right)$. Also, let $\left(\mathbb{H}_{0} \otimes\right.$ and $(\mathbb{Q} \%)$ be the optimal solutions of the duals of $\left(\mathrm{TP}_{1}\right)$ and $\left(\mathrm{TP}_{2}\right)$, respectively, where

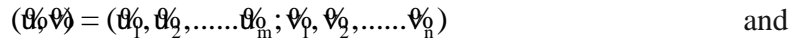

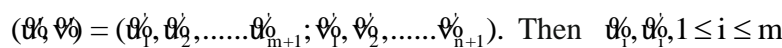
and $\nabla_{\mathrm{j}}=\dot{\nabla}_{\mathrm{\rho}}, 1 \leq \mathrm{j} \leq \mathrm{n}$ provided $\dot{\psi}_{\mathrm{m}+1}^{\dot{O}}=0$.

Proof: The problem is

$$
\begin{aligned}
& \text { Minimize } \sum_{\mathrm{i}=1}^{\mathrm{m}+1} \sum_{\mathrm{j}=1}^{\mathrm{n}+1}\left(\varepsilon_{\mathrm{ij}} \otimes \ell_{\mathrm{i}}\right), \\
& \text { subject to } \sum_{\mathrm{j}=1}^{\mathrm{n}+1} \mathscr{Q}_{\mathrm{i}} \approx \mathscr{Q}_{\mathrm{i}}(1 \leq \mathrm{i} \leq \mathrm{m}+1) \text {, }
\end{aligned}
$$

$$
\sum_{\mathrm{i}=1}^{\mathrm{m}+1} \mathrm{Q}_{\mathrm{ij}} \approx \mathrm{b}_{\mathrm{j}}^{\circ}(1 \leq \mathrm{j} \leq \mathrm{n}+1)
$$

$$
\ell_{i j} \pm 0
$$

where

$\mathscr{Z}_{\mathrm{m}+1}=\sum_{\mathrm{i}=1}^{\mathrm{m}} \mathscr{Z}_{1}$ and $\mathscr{b}_{\mathrm{n}+1}^{o}=\sum_{\mathrm{i}=1}^{\mathrm{m}} \mathscr{Q}_{1} \oplus$ excess supply.

Since ( $\left.\mathbb{Q}_{9}\right)$ is the optimal solution of dual of $\left(\mathrm{TP}_{1}\right)$, so

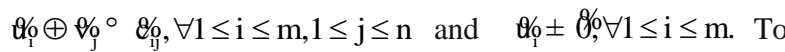

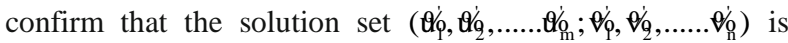
also an optimal solution of the dual of $\left(\mathrm{TP}_{1}\right)$, it is sufficient to show that

(i) $\quad \forall_{1} \oplus \theta_{j}^{\circ} \quad \varepsilon_{i j} ; \forall 1 \leq \mathrm{i} \leq \mathrm{m}, 1 \leq \mathrm{j} \leq \mathrm{n}$

(ii) $\quad \theta_{1} \pm \otimes, \forall 1 \leq \mathrm{i} \leq \mathrm{m}$. and $\theta_{0} \pm 8, \forall 1 \leq \mathrm{j} \leq \mathrm{n}$.

Since $(\mathbb{Q} b, \theta)$ is the optimal solution of the dual to problem $\left(\mathrm{TP}_{2}\right)$, so $\mathcal{H}_{1} \oplus \theta_{\mathrm{j}}^{\circ} \mathcal{E}_{\mathrm{ij}} ; \quad \forall 1 \leq \mathrm{i} \leq \mathrm{m}+1,1 \leq \mathrm{j} \leq \mathrm{n}+1$. Since $\forall_{1} \oplus \theta_{j}^{\circ} \varepsilon_{1 j}$ we have $\quad \forall_{\mathrm{m}+1} \oplus \theta_{\mathrm{j}}^{\circ} \theta_{(\mathrm{m}+1) \mathrm{j}} ; \forall 1 \leq \mathrm{j} \leq \mathrm{n}+1$ and $\quad \mathrm{q}_{1} \oplus \theta_{\mathrm{n}+1}^{\circ} \mathbb{E}_{\mathrm{in}+1)}, 1 \leq \mathrm{i} \leq \mathrm{m}+1$

$\Rightarrow \quad \theta_{\mathrm{m}+1} \oplus \theta_{\mathrm{j}}^{\circ} \theta_{(\mathrm{m}+1) \mathrm{j}} ; \forall 1 \leq \mathrm{j} \leq \mathrm{n}+1 \Rightarrow \theta_{\mathrm{j}}^{\circ} \theta_{(\mathrm{m}+1) \mathrm{j}}$

Since

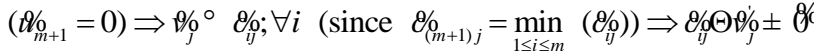
$\Rightarrow \dot{Q}_{1} \pm B c$. Similarly from $\dot{\psi}_{1} \oplus \theta_{\mathrm{n}+1} \circ \varepsilon_{1(\mathrm{n}+1)} \forall 1 \leq \mathrm{i} \leq \mathrm{m}+1$, it can be proved that $\theta_{j} \pm B^{c}$ (since $\theta_{\mathrm{m}+1}^{*}=B^{c}$ so $\theta_{\mathrm{n}+1}^{O}=B^{c}$ as $b_{n+1}^{o}$ are so chosen that in any feasible solution $\mathbb{P}(\mathrm{m}+1)(\mathrm{n}+1)$ must be a basic variable).

\section{Steps for Proposed Method}

Step 1: Balance the given ( $T_{\mathrm{P}} \mathrm{SGFTP}$ ) by adding a dummy source $\left((\mathrm{m}+1)^{\mathrm{th}}\right.$ source $)$ with availability equal to total availability as well as dummy destination $\left((\mathrm{n}+1)^{\text {th }}\right.$ destination) with demand equal to sum of total availability and excess supply. 
That is $\mathscr{Z}_{\mathrm{m}+1}=\sum_{\mathrm{i}=1}^{\mathrm{m}} \mathscr{Z}_{1}$ and $b_{\mathrm{n}+1}^{o}=\sum_{\mathrm{i}=1}^{\mathrm{m}} \mathscr{Z}_{\mathrm{o}} \oplus$ excess supply $\quad$ The unit

The unit transportation costs are taken as follows:

\begin{tabular}{|c|c|c|c|c|c|c|}
\hline Sources & $\mathbf{D}_{\mathbf{1}}$ & $\mathbf{D}_{\mathbf{2}}$ & $\mathbf{D}_{\mathbf{3}}$ & $\mathbf{D}_{\mathbf{4}}$ & $\mathbf{D}_{\mathbf{5}}$ & Supply \\
$\mathrm{S}_{1}$ & 0.950 & 0.667 & 0.507 & 1.879 & 0.507 & $\mathbf{2 . 3 3 3}$ \\
$\mathrm{S}_{2}$ & 1.587 & 1.544 & 1.652 & 1.847 & 1.544 & $\mathbf{1 . 7 3 9}$ \\
$\mathrm{S}_{3}$ & 1.371 & 1.631 & 1.652 & 1.026 & 1.026 & $\mathbf{1 . 8 4 7}$ \\
$\mathrm{S}_{4}$ & 1.080 & 2.160 & 2.160 & 0.529 & 0.529 & $\mathbf{0 . 7 2 3}$ \\
$\mathrm{S}_{5}$ & 0.950 & 0.667 & 0.507 & 0.529 & 0.000 & $\mathbf{6 . 6 4 2}$ \\
Demand & $\mathbf{1 . 9 5 5}$ & $\mathbf{1 . 9 3 4}$ & $\mathbf{2 . 0 4 1}$ & $\mathbf{2 . 4 5 2}$ & $\mathbf{4 . 9 0 2}$ & \\
\hline
\end{tabular}

\section{Table-4: Balanced generalized fuzzy transportation} problem

Step 2: Apply the zero suffix method to the balanced ( $\left.\mathrm{T}_{\mathrm{P}} \mathrm{SGFTP}\right)$ obtained in step1. Let the generalized fuzzy optimal solution obtained be $\mathbb{\ell}_{\mathrm{O}}^{\circ}, 1 \leq \mathrm{i} \leq \mathrm{m}+1,1 \leq \mathrm{j} \leq \mathrm{n}+1$.

Step 3: Find the values of all the dual variables $\mathrm{U}_{i}^{\prime}, 1 \leq \mathrm{i} \leq \mathrm{m}$ and $\dot{\theta}_{\rho}, 1 \leq \mathrm{j} \leq \mathrm{n}+1$ by assuming

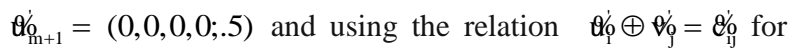
basic variables.

$$
\begin{aligned}
& \varepsilon_{1(\mathrm{n}+1)}=\min _{1 \leq \mathrm{j} \leq \mathrm{n}}\left(\&_{\mathrm{i} j}\right), 1 \leq \mathrm{i} \leq \mathrm{m}, \quad \varepsilon_{(\mathrm{m}+1) \mathrm{j}}=\min _{1 \leq \mathrm{i} \leq \mathrm{m}}\left(\&_{\mathrm{i} j}\right), 1 \leq \mathrm{j} \leq \mathrm{n}, \\
& \varepsilon_{\mathrm{i} j}=\varepsilon_{\mathrm{i} j}, 1 \leq \mathrm{i} \leq \mathrm{m}, 1 \leq \mathrm{j} \leq \mathrm{n}, \text { and } \quad \varepsilon_{(\mathrm{m}+1)(\mathrm{n}+1)}=\min _{1 \leq \mathrm{i} \leq \mathrm{m}}(0,0,0,0 ; .5) .
\end{aligned}
$$

Step4: By theorem1, $\quad \otimes_{1}=\uplus_{0}, 1 \leq \mathrm{i} \leq \mathrm{m} \quad$ and $\theta_{\rho}=\theta_{\rho}, 1 \leq \mathrm{j} \leq \mathrm{n}$, we find those dual variables and \&io and Oiphich have central rank zero. Now, we obtained the generalized fuzzy optimal solution of the problem in terms of original sources and destinations.

Let $\ell_{(\mathrm{m}+1) \mathrm{p}}$ for some $\mathrm{p}$ and $\ell_{\mathrm{q}(\mathrm{n}+1)}$ for some $\mathrm{q}$ be the basic variables in the fuzzy optimal solution obtained in step2. Also, let $\boldsymbol{U}_{1}^{\prime}$ and $\vartheta_{1}$ have rank zero for $i \in I$ and $j \in J$. Then increase the value of the basic variable in the cell with $\min _{\mathrm{i} \in \mathrm{I}} \varepsilon_{\mathrm{ip}}$ by $\ell_{(\mathrm{m}+1) \mathrm{p}}$ by $\otimes_{(\mathrm{m}+1) \mathrm{p}}$ and the value of $\min _{j \in I} E_{q j}$ by $\mathbb{Q}_{\mathrm{q}(\mathrm{n}+1)}$. Divide the tie value in minimum value(s) arbitrarily. If the minimum cost cell is non-basic in the optimal solution obtained in step2, then it may become basic in the final solution. According to the proposed method the final transportation table with $\mathrm{x}_{\mathrm{ij}}$ is as follows:

\begin{tabular}{|c|c|c|c|c|c|c|}
\hline Sources & $\mathbf{D}_{\mathbf{1}}$ & $\mathbf{D}_{\mathbf{2}}$ & $\mathbf{D}_{\mathbf{3}}$ & $\mathbf{D}_{\mathbf{4}}$ & $\mathbf{D}_{\mathbf{5}}$ & Supply \\
$\mathbf{S}_{\mathbf{1}}$ & 0.950 & $0.667(\mathbf{0 . 3 0 3})$ & $0.507(\mathbf{2 . 0 3 0})$ & 1.879 & 0.507 & $\mathbf{2 . 3 3 3}$ \\
$\mathbf{S}_{\mathbf{2}}$ & $1.587(\mathbf{0 . 1 0 8})$ & $1.544(\mathbf{1 . 6 3 1})$ & 1.652 & 1.847 & 1.544 & $\mathbf{1 . 7 3 9}$ \\
$\mathbf{S}_{\mathbf{3}}$ & $1.371(\mathbf{1 . 8 4 7})$ & 1.631 & 1.652 & 1.026 & 1.026 & $\mathbf{1 . 8 4 7}$ \\
$\mathbf{S}_{\mathbf{4}}$ & 1.080 & 2.160 & 2.160 & $0.529(\mathbf{0 . 7 2 3})$ & 0.529 & $\mathbf{0 . 7 2 3}$ \\
$\mathbf{S}_{\mathbf{5}}$ & 0.950 & 0.667 & $0.507(\mathbf{0 . 0 1 1})$ & $0.529(\mathbf{1 . 7 2 9})$ & $0.000(\mathbf{4 . 9 0 2})$ & $\mathbf{6 . 6 4 2}$ \\
Demand & $\mathbf{1 . 9 5 5}$ & $\mathbf{1 . 9 3 4}$ & $\mathbf{2 . 0 4 1}$ & $\mathbf{2 . 4 5 2}$ & $\mathbf{4 . 9 0 2}$ & \\
\hline
\end{tabular}

\begin{tabular}{|c|c|c|c|c|c|c|}
\hline $\begin{array}{c}\text { Sources } \\
S_{1}\end{array}$ & $\begin{array}{c}\mathbf{D}_{\mathbf{1}} \\
(5,7,3,4)\end{array}$ & $\frac{\mathbf{D}_{\mathbf{2}}}{(34)}$ & $\begin{array}{c}\mathbf{D}_{\mathbf{3}} \\
(2,1,4,9)(\mathbf{3 1}, \mathbf{1 6}, \mathbf{2 , 0})\end{array}$ & $\begin{array}{c}\mathbf{D}_{\mathbf{4}} \\
(9,8,14,1)\end{array}$ & $\begin{array}{c}\mathbf{D}_{5} \\
(2.1,4,9)\end{array}$ & Supply \\
\hline $\begin{array}{l}{ }_{1} \\
s_{2}\end{array}$ & $(12,11,6,2)(\mathbf{2}, \mathbf{9}, \mathbf{- 5}, \mathbf{- 1 1})$ & $(15,9,6,4)(\mathbf{2 7}, \mathbf{1 5}, \mathbf{- 2 , 3})$ & $(10,9,8,7)$ & $(14,10,11,8)$ & $(15,9,6,4)$ & $\begin{array}{c}(10,9,10,14) \\
(16,10,7,5)\end{array}$ \\
\hline $\mathbf{S}_{\mathbf{3}}$ & $(4,9,6,7)(\mathbf{1 4}, \mathbf{1 3}, \mathbf{4}, \mathbf{1 2})$ & $(1,8,9,15)$ & $(13,12,3,11)$ & $(8,7,4,1)$ & $(8,7,4,1)$ & $(14,13,4,12)$ \\
\hline $\mathbf{S}_{4}$ & $(6,3,9,4)$ & $(8,10,12,15)$ & $(8,10,12,15)$ & $(11,1,2,3)(\mathbf{1 2}, \mathbf{2}, \mathbf{3}, \mathbf{4})$ & $(11,1,2,3)$ & $(12,2,3,4)$ \\
\hline $\mathbf{s}_{\mathbf{5}}$ & $(5,7,3,4)$ & $(3,2,4,7)$ & $(2,1,4,9)(\mathbf{1 5}, \mathbf{1 2}, \mathbf{- 1 1}, \mathbf{- 1 8})$ & $(11,1,2,3)(\mathbf{1 2}, \mathbf{9}, \mathbf{1 1}, \mathbf{- 2})$ & $(0,0,0,0)(\mathbf{7 2}, \mathbf{3 4}, \mathbf{8}, \mathbf{8})$ & $(52,34,29,35)$ \\
\hline$\overline{\text { Demand }}$ & $\overline{(14,13,8,3)}$ & $\overline{(17,11,8,6)}$ & $\overline{(15,14,5,13)}$ & $\overline{(16,12,13,10)}$ & $\overline{(72,34,8,8)}$ & \\
\hline
\end{tabular}

Table-5: Solution of balanced generalized fuzzy transportation problem by zero suffix method

Table-6: Solution of balanced generalized fuzzy transportation problem

The fuzzy optimal solutions are

$$
\begin{array}{ll}
X_{12}=(14,13,-7,-21), & X_{13}=(31,16,2,0), \\
X_{21}=(2,9,-5-11), & X_{22}=(27,15,-2,3), \\
X_{31}=(14,13,4,12), & X_{44}=(12,2,3,4), \\
X_{53}=(15,12,-11,-18), & X_{54}=(12,9,11,-2) \\
X_{55}=(72,34,29,35) . &
\end{array}
$$

The total generalized fuzzy optimal cost is

$$
\mathrm{z}=
$$$$
102,543,1303)
$$

\section{CONCLUSION}

The centroid ranking technique to convert generalized fuzzy number into simple crisp number, which one concludes by example, is more suitable. Moreover the fuzzy transportation cost and fuzzy optimal cost considered here as generalized fuzzy numbers is more effective by proposed method.

\section{REFERENCES}

[1] Abbasbandy S. and Hajjari T., A new approach for ranking of trapezoidal fuzzy numbers, Computers and Mathematics with Applications, 57 (2009), 413-419.

[2] Appa G M, The transportation problem and its variants. Operation. Research. Quarterly. 24 (1973), 79-99. 
[3] Arsham H. and Khan A. B., A simplex-type algorithm for general transportation problems: An alternative to stepping stone. Jl. Operation Research Society, 40(1989) , 581-59.

[4] Basirzadeh H., An approach for solving fuzzy transportation problem. Appl. Math. Sci. 5: (2011), $1549-1566$.

[5] Bellman R.E. and Zadeh L.A., Decision-making in a fuzzy environment, Management Science, 17 (1970), B141-B164.

[6] Chanas S. and Kuchta D., A concept of the optimal solution of the transportation problem with fuzzy cost coefficients, Fuzzy Sets and Systems, 82 (1996), 299305 .

[7] Das M. K. and Baruah H. K., Solution of the transportation problem in fuzzified form. Jl. Fuzzy Math. 15 (2007), 79-95

[8] De P.K. and Yadav B., Approach to defuzzify the trapezoidal fuzzy number in transportation problem. Inter. Jl. Compt. Cognit. 8 (2010), 64-67.

[9] Dinagar D.S., Palanivel K. "The transportation problem in fuzzy environment", International journal of algorithms, computing and mathematical , (2009), 5571.

[10] Ebrahimnejad A. and Nasseri S. H., Using complementary slackness property to solve linear programming with fuzzy parameters. Fuzzy Information Eng. 3 (2009) 233-245.

[11] Fortemps P. and Roubens M., Ranking and defuzzification method based on area compensation, fuzzy sets and systems, 82 (1996), 319-330.

[12] Gani A N, Samuel A. E. and Anuradha D., Simplex type algorithm for solving fuzzy transportation problem. Tamsui Oxford Jl. Math. Sci. 27 (2011), 89-98

[13] Hitchcock F. L., The distribution of a product from several sources to numerous localities. J. Math. Phys. 20 (1941), 224-230.

[14] Kaufmann A., Introduction to the Theory of Fuzzy Sets, Vol. I Academic Press, New York, 1976.
[15] Kaufmann A. and Gupta M.M. Introduction to Fuzzy Arithmetic's, Theory and Applications. Van Nostrand Reinhold, New York, 1985.

[16] Kaur A and Kumar A., A new method for solving fuzzy transportation problems using ranking function. Appl. Math. Model. 35 (2011), 5652-5661.

[17] Kikuchi S., A method to defuzzify the fuzzy number: Transportation problem application. Fuzzy Sets Syst. 116 (2000) 3-9.

[18] Liou T. S. and Wang M. J., Ranking fuzzy number with integral value. Fuzzy Sets System, 50 (1992), 247-255.

[19] Nagarajan R. and Solairaju A., A computing improved fuzzy optimal Hungarian. Assignment problem with fuzzy cost under Robest ranking technique, internal journal of computer application volume .6, No.4. (2010), 6-13.

[20] Oheigeartaigh, H., A fuzzy transportation algorthim, Fuzzy set and system, (1982), 235-243.

[21] Pandian P. and Natrajan G., A new algorithm for finding a fuzzy optimal solution for fuzzy transportation problems. Appl. Math. Sci. 4(2010), 79-90

[22] Pandian P. and Natrajan G., An optimal more-for-less solution to fuzzy transportation problems with mixed constraints. Appl. Math. Sci. 4 (2010a ), 1405-1415.

[23] Rani D., Gulati T.R. and Kumar A., A method for unbalanced transportation problems in fuzzy environment, Sadhana (Indian Academy of Sciences), 39 (2014), 573-581

[24] Saad O.M. and Abbas S.A., A parametric study on transportation problem under fuzzy environment. J. Fuzzy Math. 11(2003)115-124

[25] Zadeh L. A., Fuzzy sets, Information and control volume 08(1965); 338- 353.

[26] Zadeh L. A, Fuzzy sets as a basis for a theory of possibility, Fuzzy Sets and Systems, 1(1978), 3-28.

[27] Zimmerman. H.J. Fuzzy programming and linear programming with several objective functions, Fuzzy sets and systems, 1978), 45-55. 